\title{
Cautious optimism-the current role of immunotherapy in gastrointestinal cancers
}

\author{
S. Mendis MBBS BMedSci* and S. Gill MD MPH MBA*
}

\begin{abstract}
Immunotherapy has been described as the "fourth pillar" of oncology treatment, in conjunction with surgery, chemotherapy, and radiotherapy. However, the role of immunotherapy in gastrointestinal tumours is still evolving. Data for checkpoint inhibition in esophagogastric, hepatocellular, colorectal, and anal squamous cell carcinomas are expanding. In phase III trials in the second-line setting, PD-1 inhibitors have demonstrated positive results for the subset of esophageal cancers that are positive for PD-L1 at a combined positive score of 10 or more. Based on results of phase II trials, PD-1 inhibitors were approved in North America for use in PD-L1-positive chemorefractory gastric cancers, in hepatocellular carcinoma after sorafenib exposure, and in treatment-refractory deficient mismatch repair (dMMR) or high microsatellite instability (MSI-H) tumours, regardless of tissue site. Combination use of PD-1 and CTLA-4 inhibitors has been approved by the U.S. Food and Drug Administration for chemorefractory dMMR or MSI-H colorectal cancer. Responses to checkpoint inhibition are durable, particularly in the dMMR or MSI-H colorectal cancer cohort. As trials of combination immunotherapy, immunotherapy in combination with other systemic therapies, and immunotherapy in combination with other treatment modalities move forward in multiple tumour sites, cautious optimism is called for. The treatment landscape is continually changing, and expanded indications are likely to be just around the corner.
\end{abstract}

Key Words Gastrointestinal neoplasms, esophageal neoplasms, stomach neoplasms, hepatocellular cancer, colorectal neoplasms, monoclonal antibodies, immunologic antineoplastic agents, microsatellite instability

Curr Oncol. 2020 April:27(S2)59-68 www.current-oncology.com

\section{INTRODUCTION}

Recognition of the role that immunotherapy can play in cancer treatment dates back to the first reports of tumour regression with interferon published in the $1970 \mathrm{~s}^{1}$. Some have described immunotherapy as the "fourth pillar" of oncology treatment (in conjunction with surgery, chemotherapy, and radiotherapy) since novel immunotherapy with checkpoint inhibitors revolutionized the treatment landscape in melanoma ${ }^{2,3}$, but the application of immunotherapy to gastrointestinal tumours has not been as straightforward.

Key concepts in immunotherapy are that neoantigen formation, because of the presence of genetic and epigenetic mutations in cancer cells, can lead to recognition and therefore destruction of cancer cells by the immune system, and that immune checkpoints can be manipulated to evade such destruction ${ }^{4,5}$. That interplay between the cancer and the immune system is critical to the efficacy of checkpoint inhibition ${ }^{6,7}$.

Immune checkpoints facilitate $\mathrm{T}$ cell recognition of antigens as either "self" or "non-self," leading to immune tolerance or immune activation respectively ${ }^{8,9}$. Binding of CTLA- 4 on a $\mathrm{T}$ cell with its corresponding ligand on an antigen-presenting cell prevents $\mathrm{T}$ cell activation during presentation of a foreign antigen ${ }^{10}$. Within the tumour microenvironment, binding of PD-1 on a T cell with its corresponding ligand, either PD-L1 or PD-L2, on the tumour cell itself similarly promotes $\mathrm{T}$ cell anergy ${ }^{11}$. Using checkpoint inhibitors such as the CTLA-4, PD-1, and PD-L1 inhibitors to block the interactions with $\mathrm{T}$ cells that facilitate $\mathrm{T}$ cell quiescence removes the inhibitory effect, allowing $\mathrm{T}$ cells to become or remain activated and to facilitate immunemediated destruction of cancer cells. An excellent overview, with illustrative figures, of the pathways involved can be found in the article by Topalian et al. ${ }^{12}$ in Cancer Cell.

Unselected tumours outside of melanoma and renal clear-cell carcinoma have a limited response to checkpoint blockade, in part because of a lower burden of somatic mutations ${ }^{13}$. Gastrointestinal tumours typically have fewer than 10 somatic mutations per megabase ${ }^{14,15}$. A number of early immunotherapy studies enrolled only participants with PD-L1-positive tumours, defined as PD-L1 expression in $1 \%$ or more of tumour cells ${ }^{16,17}$, or a combined positive score from an assessment of PD-L1 expression in tumour 
and immune cells, finding enriched response rates ${ }^{18} . \mathrm{Pu}-$ tative predictors of response to immunotherapy are now recognized to include tumour mutational burden (TMB) ${ }^{19,20}$; neoantigen load ${ }^{21}$; deficient mismatch repair (dMMR) or high microsatellite instability (MSI-H), which are surrogates for high $\mathrm{TMB}^{22,23}$; $\mathrm{T}$ cell infiltrate ${ }^{19,24}$; and PD-L1 expression, quantified by various means ${ }^{19}$.

Phase II and III clinical trial data for checkpoint inhibition in esophagogastric, hepatocellular, colorectal, and anal squamous cell carcinomas are expanding, and in the present review, we focus primarily on the data available in those tumour types at 30 June 2019. Response assessment uses RECIST (the Response Evaluation Criteria in Solid Tumors), version 1.1, unless otherwise stated. Biliary cancers, neuroendocrine tumours, and gastrointestinal stromal tumours are not discussed because of a current paucity of data for those sites. Our review also does not focus on the toxicities specific to immunotherapy, apart from highlighting the importance of a high index of suspicion for immune-related adverse events in patients who have received immunotherapy.

To appreciate the rapidity with which the treatment landscape is changing, it is illustrative to compare timelines for the approval of immunotherapeutic drugs for use in gastrointestinal tumours in the United States and Canada up to 30 June 2019 (Figure 1). However, it should be noted that, in Canada, approval by Health Canada does not necessarily imply access to a drug on any provincial formulary ${ }^{25}$.

\section{REVIEW}

\section{Upper Gastrointestinal Tract Cancers}

\section{Esophagogastric Cancer}

The phase IB KEYNOTE-028 trial enrolled 475 patients with PD-L1-positive ( $\geq 1 \%$ ) cancer at 20 tumour sites; Table I summarizes the data pertinent to gastrointestinal tumours. Table II summarizes phase II data for esophagogastric can- cers. Japanese patients with squamous cell carcinoma (SCC) of the esophagus who were chemorefractory or chemointolerant received nivolumab in the ATTRACTION-1 trial ${ }^{34}$. Global phase II data for the PD-1 inhibitor pembrolizumab in tumours of the esophagus and gastroesophageal junction (GEJ) come from KEYNOTE-180, which demonstrated an improved response rate in SCC and PD-L1-positive tumours as defined by a combined positive score (CPS) of 10 or great$\mathrm{er}^{18}$. The CPS is calculated by dividing the number of tumour cells, macrophages, and lymphocytes that express PD-L1 by the total number of tumour cells within the microscopic field and then multiplying by 100 .

For metastatic gastric or GEJ tumours, the single-arm multi-cohort phase II KEYNOTE-059 study assessed the use of pembrolizumab in patients who had progressed after 2 or more lines of therapy (cohort 1) or who were treatment-naïve (cohorts 2 and 3). Cohort 1 enrolled 259 patients who received pembrolizumab and who experienced a response rate of $12 \%$, with 4 of the 30 responders having MSI-H status ${ }^{33}$. The median duration of response (mDOR) was 8.4 months; the median progression free survival, 2 months; median overall survival (mos), 5.6 months; and the 12-month overall survival (OS), 23\%. In the trial, PD-L1-positivity was defined as a CPS of $1 \%$ or greater. The response rate was $16 \%$ in PDL1-positive patients and 6\% in PD-L1-negative patients. The mDOR was longer for PD-L1-positive patients than for PD-L1-negative patients (16 months vs. 7 months). Table II summarizes the results for cohorts 2 and $3^{31,32}$. Based on the KEYNOTE-059 results, the U.S. Food and Drug Administration (FDA) granted approval to pembrolizumab for patients with chemorefractory locally advanced or metastatic gastric or GEJ adenocarcinoma when the tumour expresses PD-L1 as determined by a U.S. FDA-approved test ${ }^{36}$.

Moving to phase III studies (Table III), KEYNOTE-181 evaluated pembrolizumab against investigator's choice of paclitaxel, docetaxel, or irinotecan in a global population of patients progressing after first-line therapy for advanced

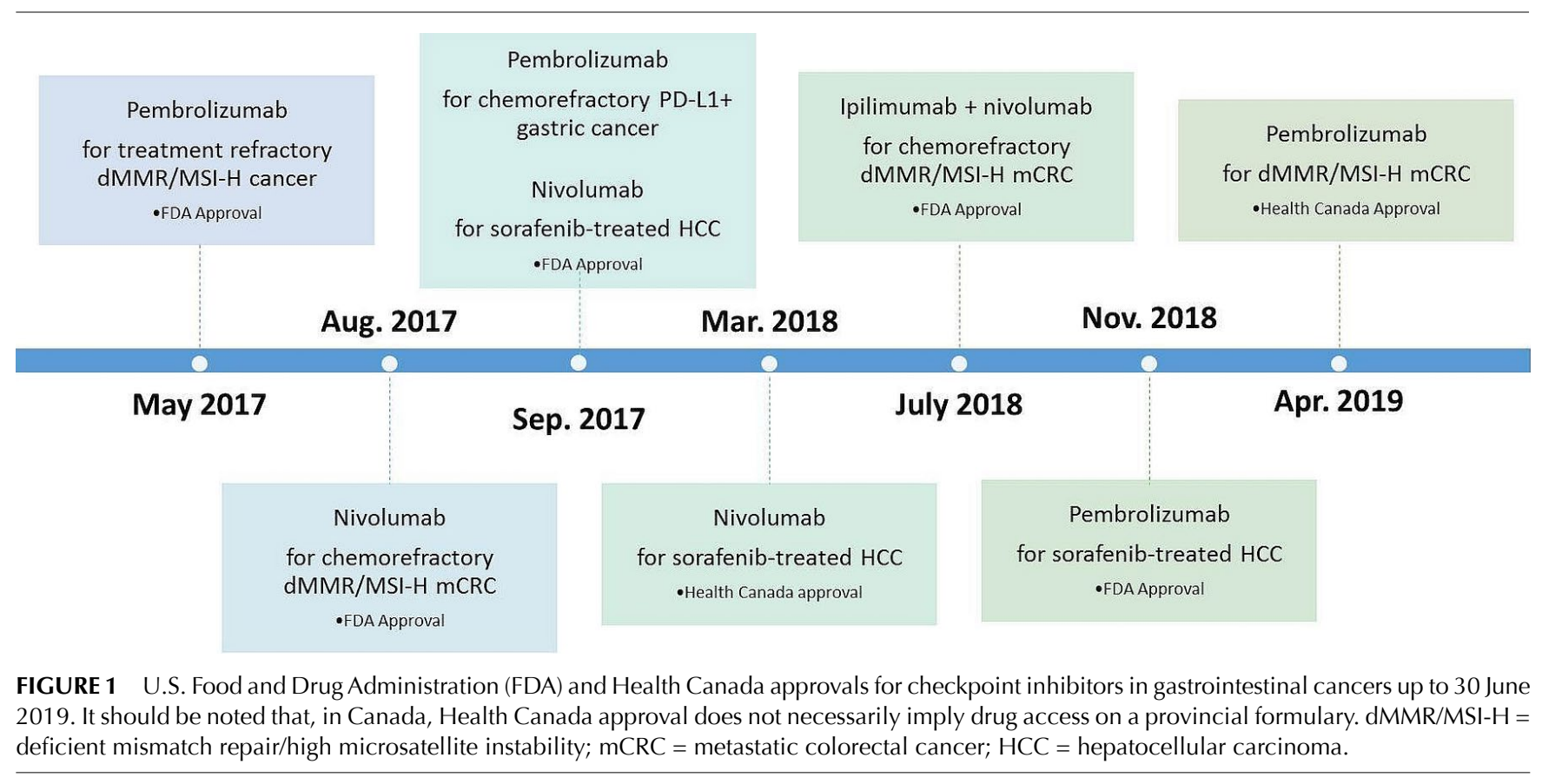


or metastatic adenocarcinoma or SCC of the esophagus or Siewert type 1 GEJ adenocarcinoma. Results were presented at the American Society of Clinical Oncology's 2019 Gastrointestinal Cancers Symposium ${ }^{40}$. The KEYNOTE-181 trial met one of its 3 co-primary endpoints of superior os with pembrolizumab in the subset of patients whose tumours had a PD-L1 CPS of 10 or greater (approximately one third of the patients enrolled). It did not meet its 2 other co-primary endpoints of improved os with pembrolizumab in the entire intention-to-treat population or in the population with

TABLE I Key phase I data for immunotherapy in gastrointestinal cancers ${ }^{\mathrm{a}}$

\begin{tabular}{|c|c|c|c|c|c|c|c|}
\hline $\begin{array}{c}\text { Reference } \\
\text { (study name) }\end{array}$ & Cancer type & $\begin{array}{l}\text { Pts } \\
\text { (n) }\end{array}$ & $\begin{array}{c}\mathbf{R R} \\
{[n(\%)]}\end{array}$ & $\begin{array}{c}\text { mDOR } \\
\text { (months) }\end{array}$ & $\begin{array}{c}\text { mPFS } \\
\text { (months) }\end{array}$ & $\begin{array}{c}\text { mOS } \\
\text { (months) }\end{array}$ & $\begin{array}{l}\text { 12-Month OS } \\
(\%)\end{array}$ \\
\hline $\begin{array}{l}\text { Muro et al., 2016 } 26 \\
\text { (KEYNOTE-012) }\end{array}$ & $\begin{array}{l}\text { Gastric or } \\
\text { GEJ carcinoma }\end{array}$ & 39 & $13(33)$ & 9.2 & 1.9 & 11.4 & 42 \\
\hline $\begin{array}{l}\text { El-Khoueiry et al., } 2017^{27} \\
\quad \text { (CheckMate 040) }\end{array}$ & $\begin{array}{l}\text { Hepatocellular } \\
\text { carcinoma }\end{array}$ & 48 & 7 (15) & 17 & 3.4 & 15 & $\begin{array}{l}\text { Not } \\
\text { reported }\end{array}$ \\
\hline $\begin{array}{l}\text { O'Neil et al., 201728; Ott et al., } 2019^{19} \\
\text { (KEYNOTE-028) }\end{array}$ & $\begin{array}{l}\text { Colorectal } \\
\text { cancer }\end{array}$ & 23 & $1(4)$ & $\begin{array}{l}\text { Not } \\
\text { reached }\end{array}$ & 1.8 & 5.3 & $\begin{array}{l}\text { Not } \\
\text { reported }\end{array}$ \\
\hline $\begin{array}{l}\text { Ott et al., 2017²9; Ott et al., } 2019^{19} \\
\text { (KEYNOTE-028) }\end{array}$ & $\begin{array}{l}\text { Anal squamous } \\
\text { cell carcinoma }\end{array}$ & 25 & 4 (17) & $\begin{array}{l}\text { Not } \\
\text { reached }\end{array}$ & 3 & 8.3 & 48 \\
\hline $\begin{array}{l}\text { Doi et al., 2018 } 30 ; \text { Ott et al., } 2019^{19} \\
\quad \text { (KEYNOTE-028) }\end{array}$ & $\begin{array}{l}\text { Esophageal or } \\
\text { GEJ carcinoma }\end{array}$ & 23 & 7 (30) & 15 & 1.8 & 7 & 40 \\
\hline
\end{tabular}

a Investigational agents: KEYNOTE trials, pembrolizumab; CheckMate trial, nivolumab. Both agents are PD-1 inhibitors. Response rate, mDOR, and $\mathrm{mPFS}$ are determined per the Response Evaluation Criteria in Solid Tumors, version 1.1.

Pts = patients; $\mathrm{RR}=$ response rate; $\mathrm{mDOR}=$ median duration of response; $\mathrm{mPFS}=$ median progression free survival; $\mathrm{mOS}=$ median overall survival; OS = overall survival; GEJ = gastroesophageal junction .

TABLE II Current phase II data for immunotherapy in esophagogastric cancers ${ }^{\mathrm{a}}$

\begin{tabular}{|c|c|c|c|c|c|c|c|}
\hline $\begin{array}{c}\begin{array}{c}\text { Reference } \\
\text { (study name) }\end{array} \\
\end{array}$ & Histology & $\begin{array}{l}\text { Line of } \\
\text { therapy }\end{array}$ & Treatment & $\begin{array}{c}\text { RR } \\
(\%)\end{array}$ & $\begin{array}{c}\text { mPFS } \\
\text { (months) }\end{array}$ & $\begin{array}{c}\text { mOS } \\
\text { (months) }\end{array}$ & $\begin{array}{c}\text { 12-Month OS } \\
(\%)\end{array}$ \\
\hline \multirow[t]{3}{*}{$\begin{array}{l}\text { Bang et al., 201731; } \\
\text { Catenacci et al., } 2017^{32} \text {; } \\
\text { Fuchs et al., 201833 } \\
\text { (KEYNOTE-059) }\end{array}$} & \multirow[t]{3}{*}{$\begin{array}{c}\text { Gastric or GEJ } \\
\text { adenocarcinoma }\end{array}$} & $3+$ & $\begin{array}{c}\text { Cohort } 1 \text { (Fuchs): } \\
\text { Pembrolizumab } 200 \text { mg } \\
\text { every } 3 \text { weeks }\end{array}$ & 12 & 2 & 5.6 & 23 \\
\hline & & 1 & $\begin{array}{l}\text { Cohort } 2 \text { (Bang): } \\
\text { Pembrolizumab } 200 \text { mg } \\
\text { every } 3 \text { weeks, plus cisplatin, } \\
\text { plus fluoropyrimidine }\end{array}$ & 60 & 6.6 & 13.8 & 52 \\
\hline & & & $\begin{array}{c}\text { Cohort } 3 \text { (Catenacci): } \\
\text { Pembrolizumab } 200 \text { mg } \\
\text { every } 3 \text { weeks }\end{array}$ & 26 & 3.3 & 20.7 & 63 \\
\hline $\begin{array}{l}\text { Kudo et al., } 2017^{34} \\
\text { (ATTRACTION-1) }\end{array}$ & $\begin{array}{l}\text { Esophageal } \\
\text { squamous cell } \\
\text { carcinoma }\end{array}$ & $2+$ & $\begin{array}{l}\text { Nivolumab } 3 \mathrm{mg} / \mathrm{kg} \\
\text { every } 2 \text { weeks }\end{array}$ & 17 & 1.5 & 10.8 & 45 \\
\hline \multirow[t]{3}{*}{$\begin{array}{l}\text { Janjigian et al., 2018 } \\
\text { (CheckMate 032) }\end{array}$} & \multirow{3}{*}{$\begin{array}{c}\text { Esophageal, } \\
\text { GEJ, or gastric } \\
\text { adenocarcinoma }\end{array}$} & $2+$ & $\begin{array}{c}\text { Nivolumab } 3 \mathrm{mg} / \mathrm{kg} \\
\text { every } 2 \text { weeks }\end{array}$ & 12 & 1.4 & 6.2 & 39 \\
\hline & & $2+$ & $\begin{array}{c}\text { Nivolumab } 1 \text {, ipilimumab 3, } \\
\text { every } 3 \text { weeks for } 4 \text { cycles, } \\
\text { then nivolumab } 3 \mathrm{mg} / \mathrm{kg} \\
\text { every } 2 \text { weeks }\end{array}$ & 24 & 1.4 & 6.9 & 35 \\
\hline & & $2+$ & $\begin{array}{c}\text { Nivolumab } 3 \text {, ipilimumab } 1, \\
\text { every } 3 \text { weeks for } 4 \text { cycles, } \\
\text { then nivolumab } 3 \mathrm{mg} / \mathrm{kg} \\
\text { every } 2 \text { weeks }\end{array}$ & 8 & 1.6 & 4.8 & 24 \\
\hline $\begin{array}{l}\text { Shah et al., } 2019^{18} \\
\text { (KEYNOTE-180) }\end{array}$ & $\begin{array}{c}\text { Esophageal } \\
\text { squamous cell } \\
\text { carcinoma or } \\
\text { adenocarcinoma; } \\
\text { Siewert type } 1 \mathrm{GEJ} \\
\text { adenocarcinoma }\end{array}$ & $3+$ & $\begin{array}{c}\text { Pembrolizumab } 200 \text { mg } \\
\text { every } 3 \text { weeks }\end{array}$ & 10 & 2 & 5.8 & 28 \\
\hline
\end{tabular}

a Pembrolizumab and nivolumab are PD-1 inhibitors. Ipilimumab is a CTLA-4 inhibitor. Response rate and mPFS are determined per the Response Evaluation Criteria in Solid Tumors, version 1.1.

$\mathrm{RR}=$ response rate; $\mathrm{mPFS}=$ median progression-free survival; $\mathrm{mOS}=$ median overall survival; $\mathrm{OS}=$ overall survival; GEJ = gastroesophageal junction; nivolumab 1 = nivolumab $1 \mathrm{mg} / \mathrm{kg}$; ipilimumab 3 = ipilimumab $3 \mathrm{mg} / \mathrm{kg}$; nivolumab 3 = nivolumab $3 \mathrm{mg} / \mathrm{kg}$; ipilimumab 1 = ipilimumab $1 \mathrm{mg} / \mathrm{kg}$. 
TABLE III Current phase III data for immunotherapy in esophagogastric cancers ${ }^{\mathrm{a}}$

\begin{tabular}{|c|c|c|c|c|c|c|c|}
\hline $\begin{array}{c}\text { Reference } \\
\text { (study name) }\end{array}$ & Histology & $\begin{array}{l}\text { Line of } \\
\text { therapy }\end{array}$ & Study arms & $\begin{array}{l}\text { RR } \\
(\%)\end{array}$ & $\begin{array}{c}\text { mPFS } \\
\text { (months) }\end{array}$ & $\begin{array}{c}\text { mOS } \\
\text { (months) }\end{array}$ & $\begin{array}{c}\text { 12-Month } \\
\text { OS } \\
(\%)\end{array}$ \\
\hline $\begin{array}{l}\text { Kang et al., } 2017^{37} \\
\text { (ATTRACTION-2) }\end{array}$ & $\begin{array}{l}\text { Gastric or GEJ } \\
\text { adenocarcinoma }\end{array}$ & $3+$ & $\begin{array}{l}\text { Investigational: } \\
\text { Nivolumab } 3 \mathrm{mg} / \mathrm{kg} \\
\text { every } 2 \text { weeks } \\
\text { Comparator: } \\
\text { Placebo }\end{array}$ & 11 vs. 0 & 1.6 vs. 1.5 & $\begin{array}{c}5.3 \text { vs. } 4.1 \\
\text { HR: } 0.63 \\
95 \% \mathrm{Cl} \\
0.51 \text { to } 0.78\end{array}$ & 26 vs. 11 \\
\hline $\begin{array}{l}\text { Bang et al., } 2018^{38} \\
\text { (JAVELIN Gastric 300) }\end{array}$ & $\begin{array}{c}\text { Gastric or GEJ } \\
\text { adenocarcinoma }\end{array}$ & 3 & $\begin{array}{c}\text { Investigational: } \\
\text { Avelumab } 10 \mathrm{mg} / \mathrm{kg} \\
\text { every } 2 \text { weeks } \\
\text { Comparator: } \\
\text { Paclitaxel or irinotecan }\end{array}$ & 2 vs. 4 & 1.4 vs. 2.7 & $\begin{array}{c}4.6 \text { vs. } 5 \\
\text { HR: } 1.1 \\
95 \% \mathrm{Cl} \text { : } \\
0.9 \text { to } 1.4\end{array}$ & $\begin{array}{l}\text { Not } \\
\text { reported }\end{array}$ \\
\hline $\begin{array}{l}\text { Shitara et al., 2018 } \\
\text { (KEYNOTE-061) }\end{array}$ & $\begin{array}{c}\text { Gastric or GEJ } \\
\text { adenocarcinoma }\end{array}$ & 2 & $\begin{array}{l}\text { Investigational: } \\
\text { Pembrolizumab 200 mg } \\
\text { every } 3 \text { weeks } \\
\text { Comparator: } \\
\text { Paclitaxel }\end{array}$ & 16 vs. 14 & 1.5. vs. 4.1 & $\begin{array}{c}9.1 \text { vs. } 8.3 \\
\text { HR: } 0.82 \\
95 \% \mathrm{Cl} \\
0.66 \text { to } 1.03\end{array}$ & 40 vs. 27 \\
\hline $\begin{array}{l}\text { Kojima et al., } 2019^{40} \\
\text { (KEYNOTE-181) }\end{array}$ & $\begin{array}{c}\text { Esophageal } \\
\text { squamous cell } \\
\text { carcinoma } \\
\text { or adenocarcinoma, } \\
\text { Siewert type } 1 \mathrm{GEJ} \\
\text { adenocarcinoma }\end{array}$ & $2+$ & $\begin{array}{l}\text { Cohort with PD-L1 CPS } \geq 10 \\
\text { Investigational: } \\
\text { Pembrolizumab } 200 \mathrm{mg} \\
\text { every } 3 \text { weeks } \\
\text { Comparator: } \\
\text { Paclitaxel, docetaxel, } \\
\text { or irinotecan }\end{array}$ & 22 vs. 6 & 2.6 vs. 3 & $\begin{array}{c}9.3 \text { vs. } 6.7 \\
\text { HR: } 0.69 \\
95 \% \mathrm{Cl} \\
0.52 \text { to } 0.93\end{array}$ & 43 vs. 20 \\
\hline $\begin{array}{l}\text { Tabernero et al., 201941 } \\
\text { (KEYNOTE-062) }\end{array}$ & $\begin{array}{c}\text { Gastric or GEJ } \\
\text { adenocarcinoma }\end{array}$ & 1 & $\begin{array}{c}\text { Investigational 1: } \\
\text { Pembrolizumab } 200 \text { mg } \\
\text { every } 3 \text { weeks }\end{array}$ & 15 vs. 37 & 2.0 vs. 6.4 & $\begin{array}{c}10.6 \text { vs. } 11.1 \\
\text { HR: } 0.91 \\
99.2 \% \mathrm{Cl} \\
0.69 \text { to } 1.18\end{array}$ & 47 vs. 46 \\
\hline & & 1 & $\begin{array}{c}\text { Investigational 2: } \\
\text { Pembrolizumab } 200 \mathrm{mg} \\
\text { every } 3 \text { weeks plus cisplatin } \\
\text { plus fluoropyrimidine } \\
\text { Comparator } 1 \text { and } 2: \\
\text { Cisplatin plus fluoropyrimidine }\end{array}$ & 49 vs. 37 & 6.9 vs. 6.4 & $\begin{array}{c}12.5 \text { vs. } 11.1 \\
\text { HR: } 0.85 \\
95 \% \mathrm{Cl} \\
0.70 \text { to } 1.03\end{array}$ & 26 vs. 19 \\
\hline
\end{tabular}

a Pembrolizumab and nivolumab are PD-1 inhibitors; avelumab is a PD-L1 inhibitor. Response rate and mPFS are determined per the Response Evaluation Criteria in Solid Tumors, version 1.1.

$\mathrm{RR}=$ response rate; $\mathrm{mPFS}=$ median progression-free survival; $\mathrm{mOS}=$ median overall survival; $\mathrm{OS}=$ overall survival; GEJ = gastroesophageal junction; $\mathrm{HR}=$ hazard ratio; $\mathrm{Cl}=$ confidence interval; $\mathrm{CPS}=$ combined positive score.

squamous histology. For patients with a PD-L1 CPS of 10 or greater, the mos with pembrolizumab was greater than that with chemotherapy [ 9.3 months vs. 6.7 months; hazard ratio (HR): $0.69 ; 95 \%$ confidence interval (CI): 0.52 to $0.93 ; p=$ 0.0074 ] , and the 12 -month os was $43 \%$ compared with $20 \%$.

For gastric or GEJ adenocarcinomas, the international KEYNOTE-062 trial compared pembrolizumab with pembrolizumab plus chemotherapy, and with placebo plus chemotherapy, in the first line for unresectable or metastatic disease that was PD-L1-positive ( $\mathrm{CPS} \geq 1$ ). Combining immunotherapy and chemotherapy might be of benefit, based on the iatrogenic effect on TMB brought about by platinum agents ${ }^{42}$. The mos with pembrolizumab monotherapy was noninferior to that with chemotherapy (10.6 months vs. 11.1 months; HR: 0.91 ; $99.2 \%$ CI: 0.69 to 1.18 ), meeting its primary endpoint ${ }^{41}$. However, the response rate and progression-free survival (PFS) were worse with pembrolizumab than with chemotherapy in the overall population with a CPS of 1 or greater-a case that did not hold in the population with a CPS of 10 or greater. Chemo- therapy plus pembrolizumab in KEYNOTE-062 was not superior to chemotherapy alone for OS (HR: $0.85 ; 95 \%$ CI: 0.70 to $1.03 ; p=0.046$ ) or PFS.

The international phase III KEYNOTE-061 trial of pembrolizumab compared with paclitaxel in the secondline setting involved 592 patients in a cohort predominantly made up of those with a PD-L1 CPS of 1 or greater ${ }^{39}$. An os benefit for pembrolizumab compared with chemotherapy could not be shown. The os curves crossed, violating the proportional hazards assumption. Although the landmark 12 -month os rate, at $40 \%$, was better for pembrolizumab-treated patients than for chemotherapy-treated patients $(27 \%)$, second-line treatment with ramucirumab-paclitaxel in the RAINBOw trial was superior to treatment with paclitaxel alone, yielding 12 -month os rates of $40 \%$ and $30 \%$ respectively ${ }^{43}$.

The phase III ATTRACTION-2 trial, conducted in Japan, South Korea, and Taiwan, compared nivolumab with placebo in 493 patients who had gastric or GEJ cancer progressing after, or intolerant to, 2 or more lines of therapy ${ }^{37}$. The mos 
was greater with nivolumab than with placebo (5.3 months vs. 4.1 months; HR: $0.63 ; 95 \%$ CI: 0.51 to $0.78 ; p<0.0001)$. The response rate and 12 -month os were $11 \%$ and $26 \%$ respectively with nivolumab; they were $0 \%$ and $11 \%$ with placebo. The population was unselected for PD-L1 staining, and a retrospective review of $39 \%$ of the cases for PD-L1 expression showed no correlation with treatment outcome. Notably, the phase III TAGS trial comparing trifluridine/ tipiracil with placebo in the third- and later-line settings also demonstrated improvement in mos to 5.7 months from 3.6 months with placebo (HR: $0.69 ; 95 \%$ CI: 0.56 to 0.85 ; one-sided $p=0.00029)^{44}$.

Another phase III trial in the third-line setting, JAVELIN Gastric 300, evaluated the PD-L1 inhibitor avelumab compared with chemotherapy for locally advanced or metastatic gastric or GEJ cancer in a worldwide population of 371 patients $^{38}$. With a response rate of $2 \%$ for avelumab and $4 \%$ for chemotherapy, and a mos of 4.6 months for avelumab and 5 months for chemotherapy (HR: 1.1; 95\% CI: 0.9 to $1.4 ; p=0.81$ ), JAVELIN Gastric 300 was a negative trial. A subgroup analysis for os stratified by PD-Ll expression did not favour either treatment arm.

Combination immunotherapy with nivolumab and the CTLA- 4 inhibitor ipilimumab in the chemorefractory setting for advanced or metastatic esophagogastric cancers was investigated in the phase I/II CheckMate 032 trial $^{35}$ in a Western population consisting of 160 patients. The response rate was $12 \%$ for nivolumab monotherapy, $24 \%$ for nivolumab $1 \mathrm{mg} / \mathrm{kg}$ and ipilimumab $3 \mathrm{mg} / \mathrm{kg}$, and $8 \%$ for nivolumab $3 \mathrm{mg} / \mathrm{kg}$ and ipilimumab $1 \mathrm{mg} / \mathrm{kg}$. Response was independent of PD-L1 status. The 12-month os rates were $39 \%$, 35\%, and $24 \%$ respectively. The phase III CheckMate 648 trial (NCT03143153 at https://ClinicalTrials.gov/), currently recruiting, is evaluating nivolumab-ipilimumab compared with nivolumab-cisplatin-5-fluorouracil (5FU) and with cisplatin-5FU in the first-line setting for advanced or metastatic SCC or adenocarcinoma of the esophagus.

To summarize the currently available trial data, PD-1 blockade has not been shown in phase III trials to be superior to chemotherapy in the first- or later-line settings for

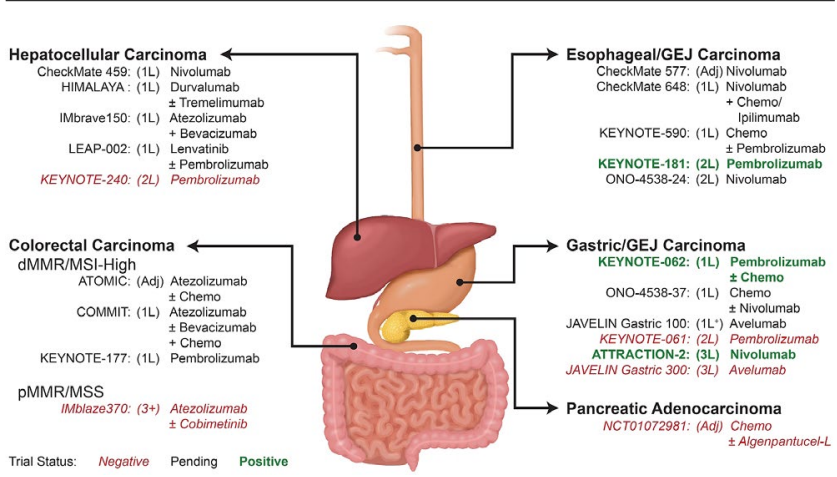

FIGURE 2 Investigational immunotherapy arms of completed and ongoing phase III trials in gastrointestinal cancers. $1 \mathrm{~L}=$ first line; $2 \mathrm{~L}=$ second line; GEJ = gastroesophageal junction; $\mathrm{Adj}=$ adjuvant; Chemo = chemotherapy; dMMR = deficient mismatch repair; MSI-High = high microsatellite instability; $1 \mathrm{~L}+=$ first-line maintenance; $3 \mathrm{~L}=$ third line; $\mathrm{pMMR}=$ proficient mismatch repair; $\mathrm{MSS}=$ microsatellite stable; $3+=$ third or later lines. patients with esophagogastric disease, with the exception of patients having esophageal or GEJ cancer with a PD-L1 CPS of 10 or greater receiving pembrolizumab in the second-line setting. For gastric cancers, PD-L1 positivity might enrich the population responding to checkpoint blockade, but has not consistently been shown to be a reliable biomarker. Non-immunotherapy strategies for gastric cancer appear to have clearer efficacy (paclitaxel-ramucirumab in the second-line setting ${ }^{43}$ and trifluridine/tipiracil in the third and later lines ${ }^{44}$ ), within the limits of cross-trial comparison. Compared with their non-Asian counterparts, Asian populations experience more favourable outcomes ${ }^{45-48}$ and better responses to immunotherapy ${ }^{40,41}$.

Results of the phase III KEYNOTE-590 trial (NCT03189719 at https://ClinicalTrials.gov/), looking at first-line cisplatin $-5 \mathrm{FU}$ with or without pembrolizumab for advanced or metastatic SCC or adenocarcinoma of the esophagus or Siewert type 1 GEJ adenocarcinoma, are awaited (Figure 2). A phase III study of nivolumab compared with docetaxel or paclitaxel in advanced or recurrent esophageal cancer is ongoing (ONO-4538-24, NCT02569242). CheckMate 577, a phase III trial of adjuvant nivolumab in patients who have residual pathologic disease at surgical resection after chemoradiotherapy for early-stage esophageal or GEJ cancer, will assess whether checkpoint inhibition has a role in the adjuvant setting.

With respect to gastric cancer, ongoing first-line trials include JAVELIN Gastric 100 (NCT02625610), which is looking at the use of avelumab as maintenance after 12 weeks of first-line 5FU-oxaliplatin, and ONO-4538-37(NCT02746796), which is looking at the addition of nivolumab to first-line fluoropyrimidine and oxaliplatin therapy. Currently, neither the U.S. FDA nor Health Canada has approved immunotherapy in esophageal cancer, although that situation might change, given results from KEYNOTE-181 in tumours with a PD-L1 CPS of 10 or greater; the current FDA indication is only for PD-L1-expressing chemorefractory gastric or GEJ adenocarcinomas.

\section{Pancreatic Cancer}

Pancreatic adenocarcinoma has a notoriously poor prognosis; patients with metastatic cancer have a $2 \% 5$-year survival rate ${ }^{49}$. Single-agent immunotherapy has had little success in that cohort, and multiple combination strategies are being trialled ${ }^{50-52}$. The results of the Canadian Cancer Trials Group PA.7 trial (NCT02879318 at https:// ClinicalTrials.gov/), a phase II trial investigating the addition of the PD-L1 inhibitor durvalumab and the CTLA-4 inhibitor tremelimumab to gemcitabine-nab-paclitaxel in untreated metastatic pancreatic ductal adenocarcinoma, are awaited to assess whether combination immunotherapy in addition to chemotherapy can improve $\mathrm{os}^{53}$.

\section{Hepatocellular Carcinoma}

Hepatocellular carcinoma (HCC) is an immunogenic tumour with an intratumoural accumulation of CD8+ T cells, but the concomitant presence of PD-1 is associated with impaired effector $\mathrm{T}$ cell function ${ }^{54-56}$. Moreover, increased PD-L1 expression in HCC tumours has been correlated with poorer disease-free survival and $0 s^{55,57}$, creating the perfect conditions for checkpoint inhibition to succeed. Nivolum- 
ab and pembrolizumab both have U.S. FDA approval for use in patients with HCC previously treated with sorafenib. The first Health Canada approval for checkpoint inhibitors in gastrointestinal cancers has also been for nivolumab in patients with HCC who are intolerant to or progressing on sorafenib (Figure 1).

Approval for nivolumab was based on the results of the CheckMate 040 phase I/II trial, which enrolled sorafenibnaïve or pretreated patients and included those with hepatitis $B$ or $C^{27,58}$. In the dose-escalation phase for nivolumab (48 patients), the overall response rate by RECIST was $15 \%$, with $43 \%$ of patients having stable disease. The mDOR was 17 months; the mos, 15 months; and the 9 -month os rate, $66 \%$. In the dose-expansion phase using nivolumab $3 \mathrm{mg} / \mathrm{kg}$ (214 patients), the response rate was $20 \%$, with $45 \%$ of patients having stable disease. The mDOR was 9.9 months, and the 9 -month os was $74 \%$. Retrospective PD-L1 staining in $81 \%$ of the dose-expansion cohort revealed that $20 \%$ of tested patients had PD-L1 membrane expression on $1 \%$ or more of tumour cells. Responses were seen in 9 of 34 patients with PD-L1 expression of $1 \%$ or more $(26 \%)$ and in 26 of 140 patients with PD-L1 expression of less than $1 \%$ (19\%).

Results from KEYNOTE-224 formed the basis for pembrolizumab approval in the second line ${ }^{59,60}$. That phase II trial enrolled 104 patients Child-Pugh class A liver function to receive pembrolizumab after progression on or intolerance to sorafenib (21\% with hepatitis B, $25 \%$ with hepatitis $\mathrm{C}$ ). The response rate by RECIST was $17 \%$, with $44 \%$ of patients having stable disease. Immune-mediated hepatitis occurred in $3 \%$ of patients; no cases of viral flares were reported. The response rate by modified RECIST represented exploratory endpoints in the CheckMate 040 and KEYNOTE-224 trials: the reported rates were $19 \%$ and $16 \%$ respectively ${ }^{27,59}$. By comparison, the response rates with first-line sorafenib or lenvatinib in the REFLECT trial were $9 \%$ and $24 \%$ respectively by modified RECIST ${ }^{61}$; the response rate to second-line regorafenib in the RESORCE trial was $11 \%^{62}$.

With respect to phase III trials, a preliminary press release reported that, in CheckMate 459 (NCT02576509 at https://ClinicalTrials.gov/), a first-line study of sorafenib compared with nivolumab, statistical significance for the superiority of os with nivolumab was not reached ${ }^{63}$. The phase III KEYNOTE-240 trial in the second-line setting, though showing a response rate by RECIST (version 1.1) of $17 \%$ for pembrolizumab and $2 \%$ for placebo, and a HR of 0.78 (95\% CI not reported; $p=0.024)$, did not reach statistical significance ${ }^{64}$.

Results are awaited from HIMALAYA (NCT03298451), another phase III first-line study comparing sorafenib with durvalumab alone or in combination with tremelimumab; from IMBrave150 (NCT03434379), comparing atezolizumab (PD-L1 inhibitor) plus bevacizumab with sorafenib; and from LEAP-002 (NCT03713593), comparing the addition of pembrolizumab to lenvatinib monotherapy in the first line to see if a changing of the guard is on the horizon. Currently, no phase III trials comparing immunotherapy with targeted agents in the second line are planned.

For patients receiving liver transplantation, only case reports are available as guidance with respect to the use of checkpoint inhibition and the risk of graft failure. Of 14 reported cases in which liver-transplant recipients underwent immunotherapy with a checkpoint inhibitor, liver graft rejection occurred in 4 . In 3 cases, rejection was fatal; 4 patients demonstrated a treatment response ${ }^{65}$. The decision to use immunotherapy in this population must be taken on a case-by-case basis.

\section{Lower Gastrointestinal Tract Cancers}

\section{Colorectal Cancer}

The narrative for immunotherapy in colorectal cancer (CRC) is the story of five trials, with the major breakthrough occurring in the $4 \%$ of metastatic CRC tumours that are dMMR or MSI- $\mathrm{H}^{66}$. In the phase IB KEYNOTE-028 trial, 23 patients with metastatic CRC were enrolled, and the only response was seen in a patient with MSI-H status ${ }^{28}$. Notably, that patient experienced a pathologic complete response ${ }^{67}$.

The phase II KEYNOTE-016 trial was the one that then enrolled patients with dMMR and proficient MMR (pMMR) CRC, as well as dMMR non-CRC. Of 10 patients with dMMR CRC, 4 responded, and of 18 with pMMR CRC, none responded ${ }^{68}$. Median PFS and os were not reached in the dMMR CRC cohort, which, compared with the pMMR CRC cohort, showed impressive HRs of $0.10(p<0.001)$ and $0.22(p=0.05)$ for PFS and os respectively. Objective responses were seen in 14 of the 29 patients with non-CRC dMMR tumours $(48 \%)^{69}$. That trial was the one that firmly established dMMR status as the biomarker for checkpoint blockade in CRC and, indeed, demonstrated the relevance of that biomarker for multiple tumour sites.

Another phase II study of pembrolizumab in pretreated MSI-H CRC was KEYNOTE-164. In cohort A, whose patients had received a minimum of 2 prior therapies, the response rate was $28 \%$ (17 of 61 ), and the 6 -month PFS and os rates were $43 \%$ and $87 \%$ respectively ${ }^{70}$. Cohort B enrolled patients who had received at least 1 prior line of therapy. The response rate in that cohort was $32 \%$. The 12 -month PFs and os rates were $41 \%$ and $76 \%$ respectively ${ }^{71}$.

Based on the results of those five single-arm clinical trials (149 patients) - KEYNOTE-028 ${ }^{16}$, KEYNOTE-016 ${ }^{22}$, KEYNOTE-164 $4^{72}$, KEYNOTE-158 73 (which enrolled patients with MSI-H nOn-CRC), and KEYNOTE- $012^{26}$ (which enrolled patients with gastric, urothelial, head-and-neck, and triple-negative breast cancers), the U.S. FDA issued its first tissue-agnostic approval of a drug on 23 May $2017^{74}$. Pembrolizumab was approved for advanced or metastatic dMMR or MSI-H tumours that progress after prior treatment and for which no satisfactory alternative treatment options are available. Patients with dMMR CRC have to have received previous treatment with a fluoropyrimidine, oxaliplatin, and irinotecan. As of April 2019, Health Canada had also approved that indication.

Data for nivolumab comes from CheckMate 142 (Table IV), a phase II parallel-cohort trial involving pretreated and treatment-naïve patients with dMMR MSI-H metastatic CRC. Of 74 pretreated patients in the nivolumab monotherapy arm, 23 (31\%) experienced an objective response-again with durability. After a median follow-up of 12 months, the mDOR was not reached. For the 119 pretreated patients allocated to combination nivolumab-ipilimumab, the response rate was $55 \%$, with impressive 12 -month PFS and os rates of $71 \%$ and $85 \%$ respectively ${ }^{76}$. In the 45 treatment-naïve patients who received combination nivolumab-ipilimumab, the response rate was $60 \%$, and the 12 -month PFS and os 
TABLE IV Results from CheckMate $142^{75, a}$

\begin{tabular}{|c|c|c|c|c|c|c|}
\hline Study cohort & Treatment & $\begin{array}{l}\text { Pts } \\
(n)\end{array}$ & $\begin{array}{c}\mathbf{R R} \\
(\%)\end{array}$ & $\begin{array}{c}\text { mPFS } \\
\text { (months) }\end{array}$ & $\begin{array}{c}\text { mOS } \\
\text { (months) }\end{array}$ & $\begin{array}{c}\text { 12-Month OS } \\
(\%)\end{array}$ \\
\hline Treatment-naïve & $\begin{array}{l}\text { Nivolumab } 3 \mathrm{mg} / \mathrm{kg} \text { every } 2 \text { weeks, } \\
\text { plus ipilimumab } 1 \mathrm{mg} / \mathrm{kg} \text { every } 6 \text { weeks }\end{array}$ & 45 & 60 & Not reached & Not reached & 83 \\
\hline Pretreated & Nivolumab 3 mg/kg every 2 weeks & 74 & 31 & 14 & Not reached & 73 \\
\hline Pretreated & $\begin{array}{l}\text { Nivolumab } 3 \mathrm{mg} / \mathrm{kg} \text { every } 3 \text { weeks for } 4 \text { cycles, } \\
\text { then every } 2 \text { weeks thereafter, } \\
\text { plus ipilimumab } 1 \mathrm{mg} / \mathrm{kg} \text { every } 3 \text { weeks for } 4 \text { cycles }\end{array}$ & 119 & 55 & Not reached & Not reached & 85 \\
\hline
\end{tabular}

a Phase II trial in patients with deficient mismatch repair or high microsatellite instability metastatic colorectal cancer. Nivolumab is a PD-1 inhibitor. Ipilimumab is a CTLA-4 inhibitor. Response rate and mPFS are determined per the Response Evaluation Criteria in Solid Tumors, version 1.1. Pts = patients; $\mathrm{RR}=$ response rate; $\mathrm{mPFS}=$ median progression free survival; $\mathrm{mOS}=$ median overall survival; OS = overall survival.

rates were $77 \%$ and $83 \%$ respectively ${ }^{77}$. In the neoadjuvant setting, combination nivolumab-ipilimumab for up to 6 weeks in the phase II NICHE study was associated with major pathologic responses in all 7 patients with dMMR colon cancers, 4 of whom experienced complete responses ${ }^{78}$.

Given the extremely promising phase II data for dMMR or MSI-H CRC treated with immunotherapy, the results of KEYNOTE-177 (NCT02563002 at https://ClinicalTrials. gov/) and cOMmIT (NCT02997228), which are comparing pembrolizumab (KEYNOTE-177) or atezolizumab (COMMIT) with standard chemotherapy in the first-line setting for metastatic dMMR or MSI-H CRC, are eagerly anticipated.

Importantly, single-agent PD-1 blockade is not an effective treatment strategy for pMMR or microsatellite-stable (MSS) CRC, which accounts for almost all stage IV CRC. In KEYNOTE-028, treatment with pembrolizumab led to 0 responses in the MSs cohort. The Canadian Cancer Trials Group's phase II CO.26 trial (NCT02870920), comparing combination checkpoint inhibition using durvalumab-tremelimumab with best supportive care in a treatment-refractory CRC cohort with predominantly MSs tumours met its endpoint of superior os in the immunotherapy arm, per a $p$ value of less than 0.1 . Exploratory bioanalyses suggest that high TMB might select for a MSS population that most benefits from that strategy $y^{20,41}$.

Other combination strategies have also been trialled. On the back of promising phase IB data ${ }^{79}$, the phase III IMblaze370 (NCT02788279) trial was developed to randomize patients with chemotherapy-refractory MSS CRC to either atezolizumab, atezolizumab-cobimetinib, or regorafenib. Unfortunately, compared with regorafenib, neither immunotherapy arm showed an os benefit ${ }^{80}$. In a similar vein, the phase II MODUL trial (NCT02291289) investigated maintenance therapy with fluoropyrimidine, bevacizumab, and atezolizumab or with cobimetinib-atezolizumab after induction chemotherapy. The addition of maintenance atezolizumab showed no os difference, and the trial was halted ${ }^{81}$.

Other strategies to harness the immune system against MSs tumours are being trialled, including CEA CD3 TCB (a novel bispecific $T$ cell antibody that targets carcinoembryonic antigen on tumour cells and CD3 on T cells) alone or in combination with atezolizumab in the phase I space ${ }^{82}$.

To summarize, for dMMR or MSI-H CRC, phase III evidence for upfront PD-1 blockade with checkpoint inhibitors is pending. Phase II data support the use of pembrolizumab or nivolumab in pretreated patients with metastatic dis- ease and, from CheckMate 142, combination nivolumabipilimumab upfront and in pretreated patients. The role of immunotherapy as an adjunct to chemotherapy or locoregional strategies in the advanced setting-and its role in the adjuvant and neoadjuvant spaces-is still being explored. For MSS CRC, immunotherapy does not have an established role; assessments of combination strategies are in progress.

\section{Anal SCC}

The KEYNOTE-028 trial included an anal scC cohort, and 4 of the 25 patients in that cohort experienced a partial response with pembrolizumab ${ }^{29}$. In the 37 patients enrolled to receive nivolumab monotherapy in the phase II NCI9673 trial, which involved treatment-refractory patients, the response rate was $24 \%$, the 6 -month PFS was $38 \%$, and the median os was 11.5 months ${ }^{83}$. The Canadian Cancer Trials Group-endorsed phase II EA2165 trial, which is studying nivolumab after chemoradiotherapy for high-risk stages IIIIIB anal cancer, is currently recruiting (NCT03233711 at https://ClinicalTrials.gov/).

Looking forward, phase II trials of cancer vaccines and trials of PD-1 inhibitors alone or in combination with CTLA-4 inhibitors, LAG-3 inhibitors, CD38 inhibitors, or engineered $\mathrm{T}$ cell therapy are ongoing ${ }^{84}$. In terms of finding biomarkers for this subset of patients, NCI9673 demonstrated that responders had more CD8+ $\mathrm{T}$ cells at baseline, greater PD-L1 tumour expression, and greater PD-1 expression on CD8+ T cells.

\section{SUMMARY}

Overall, immunotherapy, predominantly with checkpoint inhibitors, is starting to make its mark on gastrointestinal tumours. Inhibitors of PD-1 have an established role in treatment-refractory dMMR tumours, a second-line indication in HCC, and approval for use in PD-L1-positive chemorefractory gastric tumours. Furthermore, combination PD-1 and CTLA-4 inhibition has been approved by the U.S. FDA for chemorefractory dMMR CRC. Responses, when they do occur, are durable. Checkpoint inhibitors are certainly no panacea at this stage, though. Phase II results require validation in phase III trials, be it in the metastatic, adjuvant, or neoadjuvant setting (Figure 2).

The biomarker story for checkpoint blockade continues to evolve. Although patients selected for dMMR or MSI-H status consistently respond to checkpoint blockade in multiple 
tumour sites because of their high TMB, PD-L1 testing has not, itself, proven to be a consistently reliable biomarker across all gastrointestinal tumour sites-and that lack of reliability is complicated by the myriad ways in which PD-L1 can be tested and classified. Exploratory analysis of potential biomarkers within KEYNOTE-028 has revealed that patients with a high TMB and high inflammatory markers characterized by a T cell-inflamed gene expression profile or PD-L1 expression identify the population with the greatest likelihood of response ${ }^{19}$

Overall, cautious optimism is called for as trials of combination immunotherapy, immunotherapy in combination with chemotherapy or targeted therapies, and immunotherapy in combination with other modalities move forward, paired with improved biomarker assessment. This is a burgeoning field, and additional indications for checkpoint inhibitor use could be just over the horizon.

\section{ACKNOWLEDGMENTS}

We thank the illustrative scientist for Figure 2, Ryan J. Nini.

\section{CONFLICT OF INTEREST DISCLOSURES}

We have read and understood Current Oncology's policy on disclosing conflicts of interest, and we declare the following interests: SG has received consulting fees from Pfizer, Bristol-Myers Squibb, and Roche. SM has no conflicts to disclose.

\section{AUTHOR AFFILIATIONS}

*Medical Oncology, BC Cancer, Vancouver, BC.

\section{REFERENCES}

1. Priestman TJ. Interferon: an anti-cancer agent? Cancer Treat Rev 1979;6:223-37.

2. Hodi FS, O'Day SJ, McDermott DF, et al. Improved survival with ipilimumab in patients with metastatic melanoma. N Engl J Med 2010;363:711-23.

3. Emens LA, Ascierto PA, Darcy PK, et al. Cancer immunotherapy: opportunities and challenges in the rapidly evolving clinical landscape. Eur J Cancer 2017;81:116-29.

4. Dunn GP, Old LJ, Schreiber RD. The three Es of cancer immunoediting. Ann Rev Immunol 2004;22:329-60.

5. Vinay DS, Ryan EP, Pawelec G, et al. Immune evasion in cancer: mechanistic basis and therapeutic strategies. Semin Cancer Biol 2015;35(suppl):S185-98.

6. Chambers CA, Krummel MF, Boitel B, et al. The role of CTLA-4 in the regulation and initiation of T-cell responses. Immunol Rev 1996;153:27-46.

7. Korman AJ, Peggs KS, Allison JP. Checkpoint blockade in cancer immunotherapy. Adv Immunol 2006;90:297-339.

8. Weber J. Immune checkpoint proteins: a new therapeutic paradigm for cancer-preclinical background: CTLA- 4 and PD-1 blockade. Semin Oncol 2010;37:430-9.

9. Chambers CA, Kuhns MS, Egen JG, Allison JP. CTLA-4-mediated inhibition in regulation of $\mathrm{T}$ cell responses: mechanisms and manipulation in tumor immunotherapy. Annu Rev Immunol 2001;19:565-94.

10. Seidel JA, Otsuka A, Kabashima K. Anti-PD-1 and anti-CTLA-4 therapies in cancer: mechanisms of action, efficacy, and limitations. Front Oncol 2018;8:86.

11. Topalian SL, Drake CG, Pardoll DM. Targeting the PD-1/B7H1(PD-L1) pathway to activate antitumour immunity. Curr Opin Immunol 2012;24:207-12.

12. Topalian SL, Drake CG, Pardoll DM. Immune checkpoint blockade: a common denominator approach to cancer therapy. Cancer Cell 2015;27:450-61.
13. Goodman AM, Kato S, Bazhenova L, et al. Tumor mutational burden as an independent predictor of response to immunotherapy in diverse cancers. Mol Cancer Ther 2017;16:2598-608.

14. Alexandrov LB, Nik-Zainal S, Wedge DC, etal. Signatures of mutational processes in human cancer. Nature 2013;500:415-21.

15. Lawrence MS, Stojanov P, Polak P, et al. Mutational heterogeneity in cancer and the search for new cancer-associated genes. Nature 2013;499:214-18.

16. Alley EW, Lopez J, Santoro A, et al. Clinical safety and activity of pembrolizumab in patients with malignant pleural mesothelioma (KEYNOTE-028): preliminary results from a non-randomised, open-label, phase $1 \mathrm{~b}$ trial. Lancet Oncol 2017;18:623-30.

17. Seiwert TY, Burtness B, Mehra R, et al. Safety and clinical activity of pembrolizumab for treatment of recurrent or metastatic squamous cell carcinoma of the head and neck (KEYNOTE-012): an open-label, multicentre, phase $1 \mathrm{~b}$ trial. Lancet Oncol 2016;17:956-65.

18. Shah MA, Kojima T, Hochhauser D, et al. Efficacy and safety of pembrolizumab for heavily pretreated patients with advanced, metastatic adenocarcinoma or squamous cell carcinoma of the esophagus: the phase 2 KEYNOTE-180 study. JAMA Oncol 2019;5:546-50.

19. Ott PA, Bang YJ, Piha-Paul SA, et al. T-Cell-inflamed geneexpression profile, programmed death ligand 1 expression, and tumor mutational burden predict efficacy in patients treated with pembrolizumab across 20 cancers: KEYNOTE-028. J Clin Oncol 2019;37:318-27.

20. Chen EX, Jonker DJ, Loree JM, et al. CCTG CO.26: updated analysis and impact of plasma-detected microsatellite stability (MSS) and tumor mutation burden (TMB) in a phase II trial of durvalumab (D) plus tremelimumab (T) and best supportive care (BSC) versus BSC alone in patients (pts) with refractory metastatic colorectal carcinoma (rmCRC) [abstract 3512]. JClin Oncol 2019;37:. [Available online at: https://ascopubs.org/doi/ abs/10.1200/JCO.2019.37.15_suppl.3512; cited2September2019]

21. Schumacher TN, Schreiber RD. Neoantigens in cancer immunotherapy. Science 2015;348:69-74.

22. Le DT, Durham JN, Smith KN, et al. Mismatch repair deficiency predicts response of solid tumors to PD-1 blockade. Science 2017;357:409-13.

23. Le DT, Kavan P, Kim TW, et al. KEYNOTE-164: pembrolizumab for patients with advanced microsatellite instability high (MSI-H) colorectal cancer [abstract 3514].JClin Oncol2018;36: [Available online at: https://ascopubs.org/doi/abs/10.1200/ JCO.2018.36.15_suppl.3514; cited 2 September 2019]

24. Chakrabarti S, Huebner LJ, Finnes HD, et al. Intratumoral CD3+ and CD8+ T-cell densities in patients with DNA mismatch repair-deficient metastatic colorectal cancer receiving programmed cell death-1 blockade. JCO Precision Oncology $2019 ;: 1-7$.

25. Ezeife DA, Truong TH, Heng DYC, Bourque S, Welch SA, Tang PA. Comparison of oncology drug approval between Health Canada and the US Food and Drug Administration. Cancer 2015;121:1688-93.

26. Muro K, Chung HC, Shankaran V, et al. Pembrolizumab for patients with PD-L1-positive advanced gastric cancer (KEYNOTE-012): a multicentre, open-label, phase $1 \mathrm{~b}$ trial. Lancet Oncol 2016;17:717-26.

27. El-Khoueiry AB, Sangro B, Yau T, et al. Nivolumab in patients with advanced hepatocellular carcinoma (CheckMate 040): an open-label, non-comparative, phase $1 / 2$ dose escalation and expansion trial. Lancet 2017;389:2492-502.

28. O'Neil BH, Wallmark JM, Lorente D, et al. Safety and antitumour activity of the anti-PD-1 antibody pembrolizumab in patients with advanced colorectal carcinoma. PLoS One 2017;12:e0189848. 
29. Ott PA, Piha-Paul SA, Munster P, etal. Safety and antitumour activity of the anti-PD-1 antibody pembrolizumab in patients with recurrent carcinoma of the anal canal. Ann Oncol 2017;28:1036-41.

30. Doi T, Piha-Paul SA, Jalal SI, et al. Safety and antitumour activity of the anti-programmed death-1 antibody pembrolizumab in patients with advanced esophageal carcinoma. J Clin Oncol 2018;36:61-7.

31. Bang YJ, Muro K, Fuchs CS, et al. KEYNOTE-059 cohort 2: safety and efficacy of pembrolizumab (pembro) plus 5-fluorouracil (5-FU) and cisplatin for first-line (1L) treatment of advanced gastric cancer [abstract 4012]. JClin Oncol 2017;35:. [Available online at: https://ascopubs.org/doi/10.1200/JCO.2017.35.15_ suppl.4012; cited 2 September 2019]

32. Catenacci DV, Wainberg ZA, Fuchs CS, et al. KEYNOTE-059 cohort 3: safety and efficacy of pembrolizumab monotherapy for first-line treatment of patients (pts) with PD-L1-positive advanced gastric/gastroesophageal (G/GEJ) cancer [abstract LBA-009]. Ann Oncol 2017;28 (suppl 3):.

33. Fuchs CS, Doi T, Jang RW, et al. Safety and efficacy of pembrolizumab monotherapy in patients with previously treated advanced gastric and gastroesophageal junction cancer: phase 2 clinical KEYNOTE-059 trial. JAMA Oncol 2018;4: el80013.

34. Kudo T, Hamamoto Y, Kato K, et al. Nivolumab treatment for oesophageal squamous-cell carcinoma: an open-label, multicentre, phase 2 trial. Lancet Oncol 2017;18:631-9.

35. Janjigian YY, Bendell J, Calvo E, et al. CheckMate-032 study: efficacy and safety of nivolumab and nivolumab plus ipilimumab in patients with metastatic esophagogastric cancer. J Clin Oncol 2018;36:2836-44.

36. United States, Department of Health and Human Services, Food and Drug Administration (FDA). FDA grants accelerated approval to pembrolizumab for advanced gastric cancer [Web page]. Silver Spring, MD: FDA; 2017. [Available at: https:// www.fda.gov/drugs/informationondrugs/approveddrugs/ ucm577093.htm; cited 19 January 2019]

37. Kang YK, Boku N, Satoh T, et al. Nivolumab in patients with advanced gastric or gastro-oesophageal junction cancer refractory to, or intolerant of, at least two previous chemotherapy regimens (ONO-4538-12, ATTRACTION-2): a randomised, double-blind, placebo-controlled, phase 3 trial. Lancet 2017;390:2461-71.

38. Bang YJ, Ruiz EY, Van Cutsem E, et al. Phase III, randomised trial of avelumab versus physician's choice of chemotherapy as third-line treatment of patients with advanced gastric or gastro-oesophageal junction cancer: primary analysis of JAVELIN Gastric 300. Ann Oncol 2018;29:2052-60.

39. Shitara K, Ozguroglu M, Bang YJ, etal. Pembrolizumab versus paclitaxel for previously treated, advanced gastric or gastrooesophageal junction cancer (KEYNOTE-061): a randomised, open-label, controlled, phase 3 trial. Lancet 2018;392:123-33.

40. Kojima T, Muro K, Francois E, et al. Pembrolizumab versus chemotherapy as second-line therapy for advanced esophageal cancer: phase III KEYNOTE-181 study [abstract 2]. J Clin Oncol 2019;37:. [Available online at: https://ascopubs.org/doi/ abs/10.1200/JCO.2019.37.4_suppl.2; cited 2 September 2019]

41. Tabernero J, Van Cutsem E, Bang YJ, et al. Pembrolizumab with or without chemotherapy versus chemotherapy for advanced gastric or gastroesophageal junction (G/GEJ) adenocarcinoma: the phase III KEYNOTE-062 study [abstract LBA4007]. JClin Oncol 2019;37:. [Available online at: https:// ascopubs.org/doi/abs/10.1200/JCO.2019.37.18_suppl. LBA4007?af=R; cited 2 September 2019]

42. Murugaesu N, Wilson GA, Birkbak NJ, et al. Tracking the genomic evolution of esophageal adenocarcinoma through neoadjuvant chemotherapy. Cancer Discov 2015;5:821-83.
43. Wilke H, Muro K, Van Cutsem E, et al. Ramucirumab plus paclitaxel versus placebo plus paclitaxel in patients with previously treated advanced gastric or gastro-oesophageal junction adenocarcinoma (RAINBOW): a double-blind, randomised phase 3 trial. Lancet Oncol 2014;15:1224-35.

44. Shitara K, Doi T, Dvorkin M, et al. Trifluridine/tipiracil versus placebo in patients with heavily pretreated metastatic gastric cancer (TAGS): a randomised, double-blind, placebocontrolled, phase 3 trial. Lancet Oncol 2018;19:1437-48.

45. Rhome RM, Ru M, Moshier E, Mazumdar M, Buckstein MH. Stage-matched survival differences by ethnicity among gastric cancer patients of Asian ancestry treated in the United States. J Surg Oncol 2019;119:737-48.

46. Bui QL, Grazziotin-Soares D, Hasiniatsy RE, et al. Metastatic stomach cancer: clinical trials in Asia and in Occident [French]. Bull Cancer 2018;105:932-43.

47. van der Wielen N, Straatman J, Cuesta MA, Daams F, van der Peet DL. Short-term outcomes in minimally invasive versus open gastrectomy: the differences between East and West. A systematic review of the literature. Gastric Cancer 2018;21:19-30.

48. Malczak P, Torbicz G, Rubinkiewicz M, et al. Comparison of totally laparoscopic and open approach in total gastrectomy with D2 lymphadenectomy-systematic review and meta-analysis. Cancer Manag Res 2018;10:6705-14.

49. Canadian Cancer Society's Advisory Committee on Cancer Statistics. Canadian Cancer Statistics 2016. Toronto, ON: Canadian Cancer Society; 2016.

50. Royal RE, Levy C, Turner K, et al. Phase 2 trial of single agent ipilimumab (anti-CTLA-4) for locally advanced or metastatic pancreatic adenocarcinoma. J Immunother 2010;33:828-33.

51. Brahmer JR, Tykodi SS, Chow LQ, et al. Safety and activity of anti-PD-L1 antibody in patients with advanced cancer. N Engl J Med 2012;366:2455-65.

52. Johansson H, Andersson R, Bauden M, Hammes S, Holdenrieder S, Ansari D. Immune checkpoint therapy for pancreatic cancer. World J Gastroenterol 2016;22:9457-76.

53. Renouf DJ, Kavan P, Dhani NC, et al. The ССTG PA.7 trial: a randomized phase II study of gemcitabine and nab-paclitaxel vs. gemcitabine, nab-paclitaxel, durvalumab, and tremelimumab as 1st line therapy in metastatic pancreatic ductal adenocarcinoma (PDAC) [abstract TPS4149]. JClin Oncol 2017;35: [Available online at: https://ascopubs.org/doi/abs/10.1200/ JCO.2017.35.15_suppl.TPS4149; cited 2 September 2019]

54. Prieto J, Melero I, Sangro B. Immunological landscape and immunotherapy of hepatocellular carcinoma. Nat Rev Gastroenterol Hepatol 2015;12:681-700.

55. Shi F, Shi M, Zeng Z, et al. PD-1 and PD-L1 upregulation promotes $\mathrm{CD} 8^{+} \mathrm{T}$-cell apoptosis and postoperative recurrence in hepatocellular carcinoma patients. Int J Cancer 2011;128:887-96.

56. Flecken T, Schmidt N, Hild S, et al. Immunodominance and functional alterations of tumor-associated antigen-specific CD8+ T-cell responses in hepatocellular carcinoma. Hepatology 2014;59:1415-26.

57. Jung HI, Jeong D, Ji S, et al. Overexpression of PD-L1 and PD-L2 is associated with poor prognosis in patients with hepatocellular carcinoma. Cancer Res Treat 2017;49:246-54.

58. United States, Department of Health and Human Services, Food and Drug Administration (FDA). FDA grants accelerated approval to nivolumab for HCC previously treated with sorafenib [Web page]. Silver Spring, MD: FDA; 2017. [Available at: https://www.fda.gov/drugs/informationondrugs/ approveddrugs/ucm577166.htm; cited 19 January 2019]

59. Zhu AX, Finn RS, Edeline J, et al. Pembrolizumab in patients with advanced hepatocellular carcinoma previously treated with sorafenib (KEYNOTE-224): a non-randomised, open-label phase 2 trial. Lancet Oncol 2018;19:940-52. 
60. United States, Department of Health and Human Services, Food and Drug Administration (FDA). FDA grants accelerated approval to pembrolizumab for hepatocellular carcinoma [Web page]. Silver Spring, MD: FDA; 2018. [Available at: https://www.fda.gov/Drugs/InformationOnDrugs/ ApprovedDrugs/ucm625705.htm; cited 20 January 2019]

61. Kudo M, Finn RS, Qin S, et al. Lenvatinib versus sorafenib in first-line treatment of patients with unresectable hepatocellular carcinoma: a randomised phase 3 non-inferiority trial. Lancet 2018;391:1163-73.

62. Bruix J, Qin S, Merle P, et al. Regorafenib for patients with hepatocellular carcinoma who progressed on sorafenib treatment (RESORCE): a randomised, double-blind, placebocontrolled, phase 3 trial. Lancet 2017;389:56-66.

63. Bristol-Myers Squibb (BMS). Bristol-Myers Squibb announces results from CheckMate-459 study evaluating Opdivo (nivolumab) as a first-line treatment for patients with unresectable hepatocellular carcinoma [online news release]. New York, NY: BMS; 2019. [Available at: https://news.bms. com/press-release/bmy/bristol-myers-squibb-announcesresults-checkmate-459-study-evaluating-opdivo-nivol; cited 7 November 2019]

64. Finn RS, Ryoo BY, Merle P, et al. Results of KeYNOTE-240: phase 3 study of pembrolizumab (Pembro) vs best supportive care (BSC) for second line therapy in advanced hepatocellular carcinoma (HCC) [abstract 4004]. J Clin Oncol 2019;37: [Available online at: https://ascopubs.org/doi/abs/10.1200/ JCO.2019.37.15_suppl.4004; cited 6 March 2020]

65. Munker S, De Toni EN. Use of checkpoint inhibitors in liver transplant recipients. United European Gastroenterol J 2018;6:970-3.

66. Battaglin F, Naseem M, Lenz HJ, Salem ME. Microsatellite instability in colorectal cancer: overview of its clinical significance and novel perspectives. Clin Adv Hematol Oncol 2018;16:735-45.

67. Sehdev A, Cramer HM, Ibrahim AA, Younger AE, O'Neil BH. Pathological complete response with anti-PD-1 therapy in a patient with microsatellite instable high, $B R A F$ mutant metastatic colon cancer: a case report and review of literature. Discov Med 2016;21:341-7.

68. Le DT, Uram JN, Wang H, et al. PD-1 blockade in tumors with mismatch-repair deficiency. NEngl J Med 2015;372:2509-20.

69. Diaz LA, Uram JN, Wang H, et al. Programmed death-1 blockade in mismatch repair deficient cancer independent of tumor histology [abstract 3003]. J Clin Oncol 2016;34: [Available online at: https://ascopubs.org/doi/abs/10.1200/ JCO.2016.34.15_suppl.3003; cited 2 September 2019]

70. Diaz L, Marabelle A, Kim TW, et al. Efficacy of pembrolizumab in phase 2 KEYNOTE-164 and KEYNOTE-158 studies of microsatellite instability high cancers [abstract 386P]. Ann Oncol 2017;28(suppl 5):

71. Le DT, Kavan P, Kim TW, et al. KEYNOTE-164: pembrolizumab for patients with advanced microsatellite instability high (MSI-H) colorectal cancer [abstract 3514].JClin Oncol 2018;36: [Available online at: https://ascopubs.org/doi/abs/10.1200/ JCO.2018.36.15_suppl.3514; cited 2 September 2019]

72. Le DT, Andre T, Kim TW, et al. KEYNOTE-164: phase 2 study of pembrolizumab for patients with previously treated, microsatellite instability-high advanced colorectal carcinoma [abstract TPS3631]. JClin Oncol 2016;34:. [Available online at: https://ascopubs.org/doi/abs/10.1200/JCO.2016.34.15_suppl. TPS3631; cited 2 September 2019]

73. Schellens JHM, Marabelle A, Zeigenfuss S, et al. Pembrolizumab for previously treated advanced cervical squamous cell cancer: preliminary results from the phase 2 KEYNOTE-158 study [abstract 5514]. JClin Oncol 2017;35:. [Available online at: https://ascopubs.org/doi/abs/10.1200/JCO.2017.35.15_ suppl.5514; cited 2 September 2019]

74. United States, Department of Health and Human Services, Food and Drug Administration (FDA). FDA grants accelerated approval to pembrolizumab for first tissue/site agnostic indication [online news release]. Silver Spring, MD: FDA; 2017. [Available at: https://www.fda.gov/drugs/resourcesinformation-approved-drugs/fda-grants-acceleratedapproval-pembrolizumab-first-tissuesite-agnostic-indication; cited 15 February 2019]

75. Overman MJ, McDermott R, Leach JL, et al. Nivolumab in patients with metastatic DNA mismatch repair-deficient or microsatellite instability-high colorectal cancer (CheckMate 142): an open-label, multicentre, phase 2 study. Lancet Oncol 2017;8:1182-91.

76. Overman MJ, Lonardi S, Wong KYM, et al. Durable clinical benefit with nivolumab plus ipilimumab in DNA mismatch repair-deficient/microsatellite instability-high metastatic colorectal cancer. J Clin Oncol 2018;36:773-9.

77. LenzHJJ, Van Cutsem E, Limon ML, etal. Durable clinical benefit with nivolumab (NIVO) plus low-dose ipilimumab (IPI) as firstline therapyin microsatellite instability-high/mismatch repair deficient (MSI-H/dMMR) metastatic colorectal cancer (mCRC) [abstract LBA18_PR]. Ann Oncol 2018;29(suppl 8):. [Available online at: https://www.annalsofoncology.org/article/S09237534(19)50410-0/fulltext; cited 2 September 2019]

78. Chalabi M, Fanchi LF, Van den Berg JG, et al. Neoadjuvant ipilimumab plus nivolumab in early stage colon cancer [abstract LBA37_PR]. Ann Oncol 2018;29(suppl 8):. [Available online at: https://www.annalsofoncology.org/article/S09237534(19)50438-0/fulltext; cited 2 September 2019]

79. Bendell JC, Bang YJ, Chee CE, et al. A phase IB study of safety and clinical activity of atezolizumab (A) and cobimetinib (C) in patients (pts) with metastatic colorectal cancer (mCRC) [abstract 560]. J Clin Oncol 2018;36:. [Available online at: https://ascopubs.org/doi/10.1200/JCO.2018.36.4_suppl.560; cited 2 September 2019]

80. Bendell J, Ciardiello F, Tabernero J, et al. Efficacy and safety results from IMblaze370, a randomised phase III study comparing atezolizumab+cobimetinib and atezolizumab monotherapyvs regorafenib in chemotherapy-refractory metastatic colorectal cancer [abstract LBA-004]. Ann Oncol 2018;29(suppl5):. [Available online at: https://www.annalsofoncology.org/article/ S0923-7534(19)34066-9/fulltext; cited 2 September 2019]

81. Grothey A, Tabernero J, Arnold D, et al. Fluoropyrimidine (FP) + bevacizumab (BEV) + atezolizumab vs FP/BEV in BRAF Wt metastatic colorectal cancer (mCRC): findings from cohort 2 of MODUL-a multicentre, randomized trial of biomarker-driven maintenance treatment following first-line induction therapy [abstract LBA19]. Ann Oncol 2018;29(suppl 8):. [Available online at: https://www.annalsofoncology.org/article/S09237534(19)50411-2/fulltext; cited 2 September 2019]

82. Tabernero J, Melero I, Ros W, et al. Phase IA and IB studies of the novel carcinoembryonic antigen (CEA) T-cell bispecific (CEA CD3 TCB) antibody as a single agent and in combination with atezolizumab: preliminary efficacy and safety in patients with metastatic colorectal cancer (mCRC) [abstract 3002]. J Clin Oncol 2017;35:. [Available online at: https:// ascopubs.org/doi/abs/10.1200/JCO.2017.35.15_suppl.3002; cited 2 September 2019]

83. Morris VK, Salem ME, Nimeiri H, etal. Nivolumab for previously treated unresectable metastatic anal cancer (NCI9673): a multicentre, single-arm, phase 2 study. Lancet Oncol 2017;18:446-53.

84. Johnson B, Eng C. The promise of immunotherapy in anal squamous cell carcinoma: a novel approach for an orphan disease. Clin Adv Hematol Oncol 2017;15:968-76. 